\title{
Reducing Throughput Time during Product Design
}

\author{
Jeffrey W. Herrmann and Mandar M. Chincholkar \\ Institute for Systems Research \\ University of Maryland \\ College Park, Maryland 20742
}

August 13, 2001

\begin{abstract}
This paper describes an approach that can reduce throughput time during product design. Design for production (DFP) determines how manufacturing a new product design affects the performance of the manufacturing system. This includes design guidelines, capacity analysis, and estimating throughput time. Performing these tasks early in the product development process can reduce product development time. Previous researchers have developed various DFP methods for different problem settings. This paper discusses the relevant literature and classifies these methods. The paper presents a systematic DFP approach and a manufacturing system model that can be used to estimate the throughput time of a new product. This approach gives feedback that can be used to eliminate throughput time problems. This paper focuses on products that are produced in one facility and presents an example that illustrates the approach.
\end{abstract}

Keywords. design for manufacture, design for production, concurrent engineering, throughput time, queuing models 


\section{Introduction}

Product development teams (also known as integrated product and process teams) employ many methods and tools as they design, test, and manufacture a new (or improved) product. Many manufacturers now realize that time is a critical and valuable commodity. Developing a new product and bringing it to market requires a large amount of time, and delays in this time-to-market can cost a manufacturer much profit. The throughput time (sometimes called the flow time) is the interval that elapses as the manufacturing system performs all of the operations necessary to complete a work order. This throughput time has many components, including move, queue, setup, and processing times. Reducing the throughput time has many benefits, including lower inventory, reduced costs, improved product quality (process problems can be found more quickly), faster response to customer orders, and increased flexibility. In addition, a shorter throughput time means that the first batch of finished goods will reach the customers sooner, which helps reduce the time-to-market.

Much effort is spent to reduce throughput time by improving manufacturing planning and control systems and developing more sophisticated scheduling procedures, and these efforts have shown success. However, it is clear that the product design, which requires a specific set of manufacturing operations, has a huge impact on the throughput time. Product development teams would benefit from methods that can estimate the throughput time of a given product design. If the predicted throughput time is too large, the team can reduce the time by redesigning the product or modifying the production system. Estimating the throughput time early in the product development process would help reduce the total product development time (and time-to-market) by avoiding redesigns later in the process. Thus, the product development team could include this activity in their concurrent engineering approach as they address other life cycle concerns, including testing, service, and disposal.

Since a large portion of throughput time is due to queuing, and queuing occurs at heavily utilized resources, evaluating the capacity of production system resources is closely related to the issue of estimating throughput times. In addition, a production system may have insufficient available capacity to achieve the desired throughput. In this paper, the term design for production (DFP) describes methods that evaluate a product design by comparing its manufacturing requirements to available capacity and estimating throughput time. DFP can also suggest improvements that decrease capacity requirements (which can increase the maximum possible output), reduce the throughput time, or otherwise simplify production.

DFP will become more important as product variety increases and product life cycles decrease. Factories are faced with an explosion of varying throughput times because of increased product variety, and historical throughput times will not be accurate enough for a 
new product to be manufactured in the future, when the product mix will be different. Also, because production lines outlive individual products, it is important to design new products that can be manufactured quickly using existing equipment.

Previous researchers have developed various DFP methods for different problem settings. This paper discusses the relevant literature and classifies these methods. The paper's primary contribution is to present a systematic and rigorous DFP approach that quantifies how introducing a new product increases congestion in the factory. This approach employs an approximate queuing network model that estimates the throughput time of the new product. This provides feedback that the product development team can use to reduce throughput time. This paper focuses on products that are produced in one facility and provides an example that demonstrates the approach.

Note that many authors use the terms manufacturing cycle time or flow time instead of throughput time. However, this paper will use the term throughput time exclusively.

Section 2 discusses design for manufacturing approaches, while Section 3 discusses previous work on DFP methods. Section 4 presents a systematic DFP approach that estimates throughput time. Section 6 describes an illustrative example. Section 7 concludes the paper.

\section{Design for Manufacturing}

Design for manufacturing methodologies are used to improve a product's manufacturability. Three important issues dominate the discussion of design for manufacturing (DFM), also called design for manufacturability. Can the manufacturing process feasibly fabricate the specified product design? How much time does the manufacturing operation require? How much does the operation cost? (For this discussion, we will use the term manufacturing to describe both fabrication and assembly, and we will include design for assembly as part of design for manufacturing.)

DFM guidelines help a product development team design a product that is easy to manufacture, while other DFM approaches evaluate the manufacturability (feasibility, time, and cost) of a given product design with respect to a specific manufacturing process. Some manufacturability evaluation approaches give the product development team feedback on what aspects of the design make it infeasible or difficult to manufacture.

DFM compares a product's manufacturing requirements to existing manufacturing capabilities and measures the processing time and cost. DFM approaches can be used during the conceptual design and the detailed design steps. Generally, DFM approaches focus on the individual manufacturing operations. For examples and more information see Boothroyd et al. [4], Bralla [5], and Kalpakjian [22]. DFM has been very useful for reducing the unit 
manufacturing cost of many products, and successful product development processes require tools like DFM [34].

In an attempt to increase the awareness of manufacturing considerations among designers, leading professional societies and some manufacturing firms have published a number of manufacturability guidelines for a variety of manufacturing processes [1, 3, 5, 30, 39]. Researchers have developed several different approaches to evaluate manufacturability of a given design. Existing approaches can be classified roughly as follows:

Direct or rule-based approaches $[20,21,32]$ evaluate manufacturability from direct inspection of the design description: design characteristics that improve or degrade the manufacturability are represented as rules, which are applied to a given design in order to estimate its manufacturability. Most existing approaches are of this type. Direct approaches do not involve planning, estimation, or simulation of the manufacturing processes involved in the realization of the design.

Indirect or plan-based approaches $[14,15,17,19,28]$ do a much more detailed analysis: they proceed by generating a manufacturing plan and examine the plan according to criteria such as cost and processing time. If there is more than one possible plan, then the most promising plan should be used for analyzing manufacturability, and some plan-based systems generate and evaluate multiple plans $[12,13]$. The plan-based approach involves reasoning about the processes involved in the product's manufacture.

The direct approach appears to be more useful in domains such as near-net shape manufacturing, and less suitable for machined or electromechanical components, where interactions among manufacturing operations make it difficult to determine the manufacturability of a design directly from the design description. In order to calculate realistic manufacturability ratings for these latter cases, most of the rule-based approaches would require large sets of rules.

\section{Design for Production}

In general, DFP refers to methods that determine if a manufacturing system has sufficient capacity to achieve the desired throughput and methods that estimate the throughput time. These methods require information about a product's design, process plan, and production quantity along with information about the manufacturing system that will manufacture the product.

Both DFM and DFP are related to the product's manufacture. DFM evaluates the materials, the required manufacturing processes, and the ease of assembly. In short, it evaluates manufacturing capability and measures the manufacturing cost. And it focuses on the in- 
dividual operations that manufacturing requires. On the other hand, DFP evaluates how many parts the manufacturing system can output and how long each order will take. That is, it evaluates manufacturing capacity and measures the manufacturing time. Moreover, this approach requires information about the manufacturing system as a whole. Like DFM, DFP can lead a product development team to consider changing the product design. In addition, DFP can provoke suggestions to improve the manufacturing system.

DFM approaches that generate process plans and estimate processing times can be the first DFP step, since some DFP methods use this information. Traditional DFM approaches can also improve throughput time since they minimize the number of parts and reduce the processing time of each operation. DFP approaches are different because they focus on evaluating manufacturing capacity and throughput time.

DFP methods can be done concurrently with DFM. Boothroyd et al. [4] recommend that design for assembly analysis occur during conceptual design so that the product development team can reduce the part count. DFP at this stage will determine the capacity and throughput time savings that follow. They suggest that design for manufacture then occur during detailed design to reduce processing time and manufacturing costs. Using DFP methods here can guide these efforts by identifying the manufacturing steps where processing time reductions will significantly reduce throughput time.

Finally, DFP does not include lead time quoting, due date determination, and other order promising techniques that occur after the product design is specified.

Other researchers have used various names to describe DFP approaches, including design for existing environment [38], design for time-to-market [11], design for localization [26], design for speed [29], design for schedulability [24], and design for manufacturing system performance [36]. Some of these researchers have reported case studies in which product designs were modified to improve production.

Nielsen and Holmstrom [29] discuss reducing the variety of inbound materials and moving customization operations to the end of the manufacturing process. This requires the manufacturer to design the product so combinations of options don't increase the variety of procured material and to design a manufacturing process that can produce any combination quickly. They discuss a case study from the automobile industry. They do not present any approach for evaluating throughput time.

Lee et al. [26] describe an inventory model that was used to determine the inventory savings achievable if the company redesigned its printers and moved customization activities from the factory to the distribution centers.

The remainder of this section will describe previous work on three areas of DFP: design guidelines, capacity analysis, and estimating throughput times. 


\subsection{Design Guidelines}

Design guidelines help the product development team create a better product design. Many design guidelines exist for specific manufacturing processes, and they remind designers to leave sufficiently large corner radii, to avoid undercuts, and to minimize the number of components, for example.

Kusiak and He [24] suggest rules that designers can follow to reduce a product's throughput time. In addition, these rules attempt to simplify the production scheduling problems that plague most production systems. For example, the rules state that one should minimize the number of machines needed to manufacture a product (which yields fewer moves and less queue time) and allow the use of substitute manufacturing processes (which gives the production system the flexibility to route an order to another operation to avoid a long queue at a bottleneck resource or unavailable machine).

\subsection{Capacity Analysis}

Capacity analysis compares the manufacturing system's capacity to the product design's requirements. The manufacturing system's capacity depends upon the time available at each required resource and the time already allocated to fabricating other products. The product design's requirements depend upon the setup and processing time at each operation and the desired production rate. Capacity analysis can determine whether sufficient capacity exists, estimate the maximum feasible production level, suggest other release dates, and suggest changes that would increase the manufacturing system capacity. Of course, the available capacity is not the same for each resource, since some resources are busier than others and sometimes there exist multiple, identical resources that can share the workload. In addition, the capacity requirements are not the same for each resource since setup and processing times can vary greatly from one operation to the next. In addition, the available capacity may change from one time period to the next as the product mix changes.

Taylor et al. [38] use a capacity analysis model to determine the maximum production quantity that an electronics assembly facility can achieve. The analysis is done for a set of existing products and the detailed design of a new product. If the maximum production quantity is insufficient, the product design is changed so that its manufacture avoids a bottleneck resource, which increases the achievable production quantity to an acceptable level. This work does not estimate throughput time.

Bermon et al. [2] present a capacity analysis model for a manufacturing line that produces multiple products. Their approach is not focused on product design but it is oriented towards decision support and quick analysis. They define available capacity as the number of operations that a piece of equipment can perform each day. Given information about 
the equipment available, the products, and the operations required, their approach allocates equipment capacity to satisfy the required throughput and availability constraints. They incorporate throughput time by constraining allocated capacity (utilization) to a level strictly below the available capacity. The difference is the contingency factor. Instead of setting this contingency factor in some ad hoc manner, as some manufacturers do, they describe a method to calculate a contingency factor for each tool group. The ideal contingency factor prevents the average queue time at that tool group from exceeding a predetermined multiple of the processing time. To model the relationship between utilization and queue time, their approach uses a queuing model approximation. Thus, their approach can determine if the manufacturing line has sufficient capacity to meet the required production and achieve reasonable throughput times.

Many authors have described capacity planning methods that are part of traditional manufacturing planning and control systems [18, 42]. These methods determine how much, when, what type, and where a manufacturing system should add capacity to meet throughput requirements. Typical objectives include minimizing equipment costs, inventory, and throughput time. Different capacity planning models vary, and the more accurate methods require more data and more computational effort. These approaches do not consider how the product design affects the manufacturing system performance.

\subsection{Estimating Throughput Time}

Previous DFP approaches estimate throughput time either by modeling the steady-state performance of the manufacturing system or by scheduling or simulating manufacturing systems that are evolving as the product mix changes over time.

Previous work on manufacturability evaluation and partner selection for agile manufacturing developed two approaches for estimating throughput time of microwave modules and flat mechanical products. Given a detailed product design, the variant approach $[7,8]$ first calculates Group Technology codes that concisely describe the product attributes. Then, this approach searches a set of existing products manufactured by potential partners and identifies the ones that have the most similar codes. The throughput time of the most similar existing products gives the product development team an estimate of the new product's throughput time.

The generative approach $[17,28]$, however, creates a set of feasible partner-specific process plans for the given product design and calculates the throughput time at each step in each plan. Given a production quantity, the approach calculates the required processing time for an order of that size and adds the processing time to historical averages for the setup and queue times at that resource in that manufacturing facility. The approach then sums these 
times over all the steps in each process plan, which gives the product development team an opportunity to see how choosing different partners affects the throughput time. This approach does not consider the available capacity that the manufacturing resources have or adjust the queue times as utilization increases.

Herrmann and Chincholkar [16] present a set of models that can be used to estimate the throughput time of a new product. The report discusses the relative merits of using fixed lead times, mathematical models, discrete-event simulation, and other techniques. Seepersad et al. [33] present a throughput time analysis of a heat-exchanger tube manufacturing facility and an approach for optimal design of these tubes using a product platform based approach.

Singh [35] calculates the time at a manufacturing operation as the sum of the setup time and the run time (the part processing time multiplied by the lot size). This approach ignores any time due to queuing or moving.

Govil [11] assumes that the throughput time at each manufacturing operation is one time period. The lead time for purchased parts may be multiple periods. This approach uses the assembly structure to create a tree of purchasing and manufacturing operations, and the throughput time is the length of the longest path through this tree.

Meyer et al. [27] describe an approach for comparing microwave module designs. Each different design uses a different set of electronic components. The approach generates process plans that are feasible with respect to the characteristics of the selected components. They evaluate each design and process plan based on the cost, the system reliability, and the maximum lead time required to procure any of the selected components.

Veeramani et al. $[40,41]$ describe a system that allows a manufacturer to respond quickly to requests for quotation (RFQs). The approach is applicable for companies that sell modified versions of standard products that have complex subassemblies (like overhead cranes). Based on customer specifications for product performance, the system generates a product configuration, a three-dimensional solid model, a price quotation, a delivery schedule, the bill of materials, and a list of potential design and manufacturing problems. The system verifies that the design can be feasibly manufactured by the shop. The authors claim that, to generate the delivery schedule for that order, the system uses data about shop floor status, current orders, and alternative process plans to determine the time needed to produce the new order. Although no details are given, it appears that the system does some shop floor scheduling to determine the completion date.

Elhafsi and Rolland [10] study a make-to-order manufacturing system and build a model that can determine the delivery date of a single customer order. The model takes into account the production lines' existing workloads and allocates portions of the order to different lines to minimize the cost and estimate the expected delivery date. Each line is modeled as a 
single-server queuing system.

The U.S. Air Force is developing the Simulation Assessment Validation Environment (SAVE), which integrates a set of virtual manufacturing tools. The SAVE program will help product development teams develop affordable weapon systems (like fighter aircraft) by giving them the ability to evaluate cost, throughput time, inventory levels, rework, and other manufacturing metrics. The SAVE approach uses detailed factory simulation models to estimate throughput time.

Soundar and Bao [36] describe a plan to address the question of determining how the product design affects the manufacturing system. They propose using mathematical and simulation models to estimate a variety of different performance measures, including throughput time. Though the approach is quite general, the paper does not describe any examples or results.

\section{Approach}

This section describes the following comprehensive DFP methodology for evaluating a product design and making redesign suggestions:

1. Create a product design that satisfies the product's functional requirements and DFP design guidelines. Specify the desired throughput and workorder (job) size.

2. For the given product design, generate a manufacturing process plan. For each operation, identify the required resources and estimate the setup and processing times.

3. Using the given data, information about other products that will be manufactured at the time the new product is introduced, and data about the manufacturing system, determine if the manufacturing system has sufficient capacity to achieve the desired production rate.

- If not, identify the throughput limiting process (workstation). Consider redesigning the product to avoid this station, redesigning the product to reduce the capacity requirements, or adding capacity to this station. If the product is redesigned, return to Step 2. If sufficient capacity is added, go to Step 4.

4. Using similar information, estimate the throughput time of the new product.

- If the throughput time is unacceptably large, identify the process (workstation) whose throughput time is the greatest or most sensitive to processing time. Consider redesigning the product to avoid this station, redesigning the product to 
reduce the processing time, or adding capacity (which will lower utilization and throughput time). If the product is redesigned, return to Step 2. If capacity is added, repeat this step.

Note that the most preferred suggestion is to change the design (inexpensive if done early) and that the least preferred suggestion is to add capacity (which can be expensive).

Capacity analysis. Section 5 presents the manufacturing system model needed for capacity analysis and estimating throughput time. Any station $j$ with utilization $u_{j} \geq 1$ has insufficient capacity to achieve the desired production rate of the existing products and the new product.

Estimating throughput time. The average throughput time of a job of product $i$ is $T T_{i}$. The manufacturing system model calculates certain quantities that can be used to identify opportunities to reduce the throughput time. In particular, the product development team should examine stations with high utilization $\left(u_{j}\right)$, large throughput time $\left(T T_{j}^{*}\right)$, large throughput time multiple $\left(M_{j}\right)$, and high sensitivity $\left(S_{i j}\right)$. (These measures are defined in the next section.)

\section{Manufacturing System Model}

We use the following queuing network model to estimate the average throughput time of products through the factory. The approximation aggregates the products and calculates the average throughput time at each station. This model uses previously described approximations $[18,23]$.

This manufacturing system model assumes that the manufacturing system will complete a large number of work orders (jobs) of the new product. No job visits a station more than once. This model assumes that the product mix and the resource availability do not change significantly over a long time horizon. If the product mix or the resource availability were changing significantly then different models may be more appropriate [16]. Of course, it may be possible to divide the time horizon into two or more periods where the system reaches steady-state. In this case, this model can be used for each time period. Alternatively, one can neglect the aspects of the system that are evolving and use the steady state model to approximate the system.

Note that a critical piece of data for estimating throughput times is the processing time of each step required to manufacture the given product design. There exist many models and techniques for estimating processing times. Many of the DFM approaches include this 
activity. Estimating the processing time of a manufacturing step given a detailed design is usually different from estimating the processing time given a conceptual design. For a detailed design, highly detailed process planning, manufacturing process simulation, or time estimation models can be employed [17, 28]. For a conceptual design, however, less detailed models must depend upon a more limited set of critical design information [11]. For existing products, the processing and setup times should be available from existing process plans.

For more information on queuing network models, see Papadopoulos et al. [31] and Buzacott and Shanthikumar [6], who present queuing network models for manufacturing systems. Connors et al. [9] modeled semiconductor wafer fabrication facilities using a sophisticated queuing network model to analyze these facilities quickly by avoiding the effort and time needed to create and run simulation models. (These models are similar to the ones used here.) They present numerical results that show how the queuing network model yields similar results to those that a simulation model yields. Queuing network models are also the mathematical foundation of manufacturing system analysis software like rapid modeling [37]. Koo et al. [23] describe software that integrates a capacity planning model and queuing network approximations. They report that the approximations are reasonable when variability is moderate. However, few researchers have described how to apply this body of work to product design and manufacturability evaluation.

Data Requirements. The manufacturing system model requires the following data: For each workstation, the number of resources available, and the mean time to failure and mean time to repair a resource; for each existing product and the new product, the job size (number of parts) and the desired throughput (number of parts per hour of factory operation); the sequence of workstations that each job must visit; the mean setup time (per job) at each workstation and its variance; the mean processing time (per part) at each workstation and its variance; the yield at each workstation that a job must visit (the ratio of good parts produced to parts that undergo processing). The squared coefficient of variation (SCV) of a random variable equals its variance divided by the square of its mean.

$$
\begin{aligned}
I & =\text { the set of all products (existing and new) } \\
T_{i} & =\text { desired throughput of product } i \text { (parts per hour) } \\
B_{i} & =\text { job size of product } i \text { at release } \\
c_{i}^{r} & =\text { SCV of job interarrival times for product } i \\
J & =\text { the set of all stations } \\
n_{j} & =\text { the number of resources at station } j
\end{aligned}
$$




$$
\begin{aligned}
m_{j}^{f} & =\text { mean time to failure for a resource at station } j \\
m_{j}^{r} & =\text { mean time to repair for a resource at station } j \\
R_{i} & =\text { the sequence of stations that product } i \text { must visit } \\
R_{i j} & =\text { the subsequence that precedes station } j \\
t_{i j} & =\text { mean part process time of product } i \text { at station } j \\
c_{i j}^{t} & =\mathrm{SCV} \text { of the part process time } \\
s_{i j} & =\text { mean job setup time of product } i \text { at station } j \\
c_{i j}^{s} & =\mathrm{SCV} \text { of the setup time } \\
y_{i j} & =\text { yield of product } i \text { at station } j
\end{aligned}
$$

Aggregation. Aggregation calculates, for each product, the processing time of each job at each station. It also calculates, for each station, the average processing time, weighted by each product's arrival rate. Finally, it modifies the aggregate processing times by adjusting for the resource availability.

$$
\begin{aligned}
Y_{i j} & =\text { cumulative yield of product } i \text { through } R_{i j} \\
Y_{i} & =\text { cumulative yield of product } i \text { through } R_{i} \\
x_{i} & =\text { release rate of product } i \text { (jobs per hour) } \\
A_{j} & =\text { availability of a resource at station } j \\
V_{j} & =\text { the set of products that visit station } j \\
t_{i j}^{+} & =\text {total process time of product } i \text { at station } j \\
c_{i j}^{+} & =\text {SCV of the total process time } \\
t_{j}^{+} & =\text {aggregate process time at station } j \\
c_{j}^{+} & =\text {SCV of the aggregate process time } \\
t_{j}^{*} & =\text { modified aggregate process time at station } j \\
c_{j}^{*} & =\mathrm{SCV} \text { of the modified aggregate process time }
\end{aligned}
$$

The cumulative yield is the product of the yields at each station that the product visits.

$$
\begin{aligned}
Y_{i j} & =\prod_{k \in R_{i j}} y_{i k} \\
Y_{i} & =\prod_{k \in R_{i}} y_{i k}
\end{aligned}
$$




$$
\begin{aligned}
x_{i} & =\frac{T_{i}}{\left(B_{i} Y_{i}\right)} \\
A_{j} & =\frac{m_{j}^{f}}{m_{j}^{f}+m_{j}^{r}} \\
V_{j} & =\left\{i \in I: j \in R_{i}\right\}
\end{aligned}
$$

The time spent by a job at station $j$ is the sum of the part processing times and the setup time. The job size depends on the cumulative yield of the preceding operations.

$$
\begin{aligned}
t_{i j}^{+} & =B_{i} Y_{i j} t_{i j}+s_{i j} \\
\left(t_{i j}^{+}\right)^{2} c_{i j}^{+} & =B_{i} Y_{i j} t_{i j}^{2} c_{i j}^{t}+s_{i j}^{2} c_{i j}^{s}
\end{aligned}
$$

Equation 7, which is used to calculate $c_{i j}^{+}$, holds because the variance of the total process time is the sum of the variance of the part process times and the variance of the job setup time. The aggregate process time of jobs at station $j$ is the weighted average of all the jobs that visit station $j$. Each product is weighted by its release rate, as shown in Equation 8 . Equation 9 calculates the mean of the square aggregate process time, which can be used to determine the SCV $c_{j}^{+}$.

$$
\begin{aligned}
t_{j}^{+} & =\frac{\sum_{i \in V_{j}} x_{i} t_{i j}^{+}}{\sum_{i \in V_{j}} x_{i}} \\
\left(t_{j}^{+}\right)^{2}\left(c_{j}^{+}+1\right) & =\frac{\sum_{i \in V_{j}} x_{i}\left(t_{i j}^{+}\right)^{2}\left(c_{i j}^{+}+1\right)}{\sum_{i \in V_{j}} x_{i}}
\end{aligned}
$$

Equations 10 and 11 modify the mean and SCV for the process times by adding the effects of resource availability.

$$
\begin{aligned}
t_{j}^{*} & =\frac{t_{j}^{+}}{A_{j}} \\
c_{j}^{*} & =c_{j}^{+}+2 A_{j}\left(1-A_{j}\right) \frac{m_{j}^{r}}{t_{j}^{+}}
\end{aligned}
$$

Arrival and Departure Processes. The arrival process at each station depends upon the products that visit the station. Some products are released directly to the station, while others arrive from other stations. The departure process depends upon the arrival process and the service process.

$$
V_{0 j}=\text { the set of products that visit station } j \text { first }
$$




$$
\begin{gathered}
V_{h j}=\text { the set of products that visit station } h \text { immediately before } j \\
\lambda_{j}=\text { total job arrival rate at station } j \\
\lambda_{h j}=\text { arrival rate at station } j \text { of jobs from station } h \\
q_{h j}=\text { proportion of jobs from station } h \text { that next visit station } j \\
c_{j}^{a}=\text { SCV of interarrival times at station } j \\
c_{j}^{d}=\text { SCV of interdeparture times at station } j \\
\lambda_{j}=\sum_{i \in V_{j}} x_{i} \\
\lambda_{h j}=\sum_{i \in V_{h j}} x_{i} \\
q_{h j}=\frac{\lambda_{h j}}{\lambda_{h}}
\end{gathered}
$$

Equations 15 and 16 estimate the SCVs for the departure and arrival processes.

$$
\begin{aligned}
c_{j}^{d} & =1+\frac{u_{j}^{2}}{\sqrt{n_{j}}}\left(c_{j}^{*}-1\right)+\left(1-u_{j}^{2}\right)\left(c_{j}^{a}-1\right) \\
c_{j}^{a} & =\sum_{h \in J}\left(\left(c_{h}^{d}-1\right) q_{h j}+1\right) \frac{\lambda_{h j}}{\lambda_{j}}+\sum_{i \in V_{0 j}} c_{i}^{r} \frac{x_{i}}{\lambda_{j}}
\end{aligned}
$$

Solving the above set of equations yields the complete set of $c_{j}^{a}$ and $c_{j}^{d}$ for all stations. If all products visit the same sequence of stations, then one can renumber the stations $1,2, \ldots, J$. $V_{j}=I$ and $V_{j-1, j}=I$ for all stations. Equation 16 can then be simplified as follows:

$$
\begin{aligned}
c_{1}^{a} & =\frac{\sum_{i \in I} c_{i}^{r} x_{i}}{\sum_{i \in I} x_{i}} \\
c_{j}^{a} & =c_{j-1}^{d}, 2 \leq j \leq J
\end{aligned}
$$

Performance Measures. The performance measures of interest are the average utilization of resources and the throughput time. The average throughput time of a job depends upon the throughput time at each station it visits.

$$
\begin{aligned}
u_{j} & =\text { the average resource utilization at station } j \\
T T_{j}^{*} & =\text { the average throughput time at station } j \\
T T_{i} & =\text { the average throughput time of jobs of product } i
\end{aligned}
$$




$$
\begin{aligned}
u_{j} & =\frac{t_{j}^{*}}{n_{j}} \sum_{i \in V_{j}} x_{i} \\
T T_{j}^{*} & =\frac{1}{2}\left(c_{j}^{a}+c_{j}^{*}\right) \frac{u_{j}^{\left(\sqrt{2 n_{j}+2}-1\right)}}{n_{j}\left(1-u_{j}\right)} t_{j}^{*}+t_{j}^{*} \\
T T_{i} & =\sum_{j \in R_{i}} T T_{j}^{*}
\end{aligned}
$$

Sensitivity. Two measures (the multiple $M_{j}$ and the sensitivity $S_{i j}$ ) indicate how the throughput time of the new product is sensitive to its part processing time at station $j$. In the general case, calculating the derivative $\frac{\partial T T_{j}^{*}}{\partial t_{i j}}$ is feasible but complex due to the equations that describe the arrival and departure processes. Thus, we use the following quantities to estimate the derivatives of interest. The multiple $M_{j}$ is an estimate for $\frac{\partial T T_{j}}{\partial t_{j}^{*}}$, and the sensitivity $S_{i j}$ is an estimate for $\frac{\partial T T_{j}^{*}}{\partial t_{i j}}$. These quantities give the product development team insight into how changes to part processing time affect the overall system performance. This can guide efforts to reduce excessive throughput time.

$$
\begin{aligned}
M_{j} & =\frac{1}{2}\left(c_{j}^{a}+c_{j}^{*}\right) \frac{u_{j}^{\left(\sqrt{2 n_{j}+2}-1\right)}}{n_{j}\left(1-u_{j}\right)}+1 \\
& =\frac{T T_{j}^{*}}{t_{j}^{*}} \\
S_{i j} & =M_{j} \frac{x_{i} B_{i} Y_{i j}}{A_{j} \lambda_{j}} \\
& =\frac{T T_{j}^{*}}{t_{j}^{*}} \frac{x_{i} B_{i} Y_{i j}}{A_{j} \lambda_{j}}
\end{aligned}
$$

Discussion. The queuing network approximations used here, all based on previously described models, offer some advantages and also have limitations. Compared to simulation models or more sophisticated queuing network analysis techniques, these approximations are less accurate, especially for very complex systems, and cannot provide the same range of performance measures. However, they require less data and less computational effort than the simulation models and other analysis techniques. Therefore, they are more appropriate for situations where a decision-maker needs to compare many scenarios quickly.

\section{Example}

This section demonstrates some of the manufacturing system models for a specific product design and manufacturing system. The product is a microwave module, and the manufacturing system is an electronics assembly shop. The information about the product and the system 


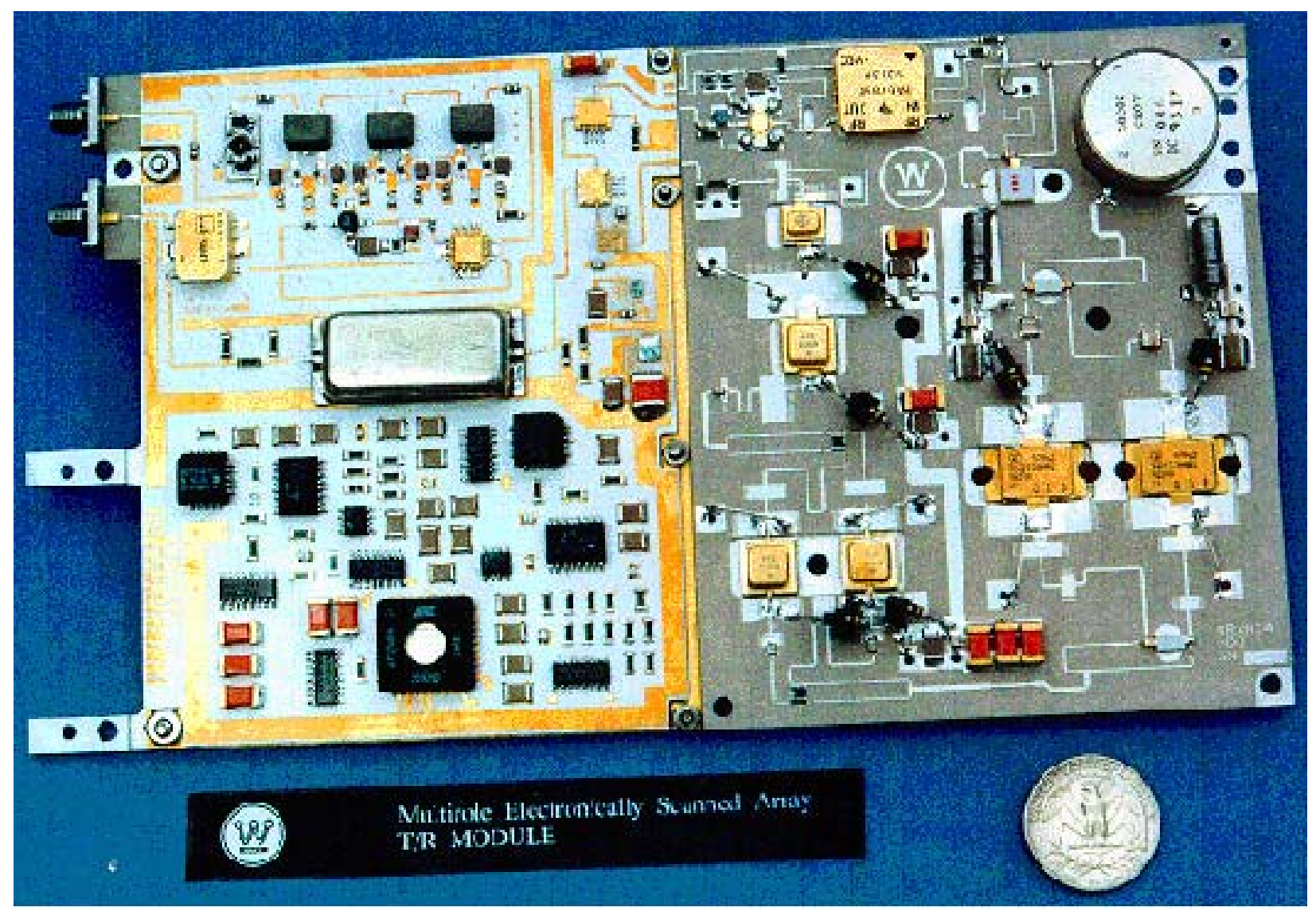

Figure 1: A microwave module

is based on our experience with an electronic systems manufacturer. This example uses data that our collaborators were able to provide and other synthetic data that we created. For details about the process planning and processing time estimation, see [17, 28].

\subsection{The Products}

Modern microwave modules (MWMs) have an artwork layer that includes many functional components of the circuit. See Figure 1. The artwork lies on the dielectric substrate, which is attached to a ground plane that also serves as a heat sink. In addition to the integrated components, MWMs may carry hybrid components, which are assembled separately using techniques such as soldering, wire bonding, and ultrasonic bonding. Mounting these components often requires holes, pockets, and other features in the substrate.

The manufacturing company currently produces two types of microwave modules (Products 1 and 2) and is developing a third (Product 3). Since the company purchases aluminum substrates that already have the dielectric layer, the process plans for all three products have the same sequence: 
Table 1: Critical Design Information

\begin{tabular}{||l|c|c|c||}
\hline Attribute & Product 1 & Product 2 & $\begin{array}{c}\text { New } \\
\text { Product }\end{array}$ \\
\hline Length (in.) & 7 & 8 & 6 \\
Width (in.) & 3.0 & 3.5 & 2.5 \\
Number of approach directions & 1 & 1 & 1 \\
Number of large pockets & 2 & 2 & 0 \\
Number of small pockets & 1 & 4 & 6 \\
Number of holes & 10 & 10 & 5 \\
Average hole depth (in.) & 0.1 & 0.1 & 0.1 \\
Plating thickness (in.) & 0.0001 & 0.0001 & 0.0001 \\
Artwork area fraction & 0.5 & 0.5 & 0.25 \\
Surface mount components & 3 & 4 & 10 \\
Other components & 1 & 1 & 4 \\
\hline
\end{tabular}

1. Machine holes and pockets.

2. Plate (electroless, or autocatalytic, plating and electroplating)

3. Etch (clean, apply photoresist, expose, develop, etch, clean)

4. Automated Assembly (mount and solder surface mount components)

5. Manual Assembly (attach other components)

6. Test (and tune as necessary)

Table 1 gives critical information about the products, and Table 2 lists the mean job processing times for each operation. The part processing times and setup times (not shown here) are calculated using previously developed rules and algorithms for MWM process planning $[17,28]$.

Each processing time has some variability as well. The part processing times of the manual assembly and test operations are exponentially distributed. The setup times are uniformly distributed and can vary by plus or minus 20 minutes. The yield at each station is 1.0.

\subsection{The Manufacturing System}

The facility manufacturing these microwave modules is a batch manufacturing system. The facility purchases the Teflon-coated aluminum substrates. There is a CNC machine tool that can machine the required holes and pockets. The facility has an electroless (autocatalytic) plating workstation, an electroplating workstation, an etch workstation, a workstation for automated assembly, and a workstation for manual assembly. The automated assembly 
Table 2: Process Plans

\begin{tabular}{||l|c|c|c|c|c||}
\hline Product $i$ & 1 & 2 & 3 & \multicolumn{2}{|c||}{ Aggregate } \\
\hline Job processing time (mins) & $t_{1 j}^{+}$ & $t_{2 j}^{+}$ & $t_{3 j}^{+}$ & $t_{j}^{*}$ & $c_{j}^{*}$ \\
\hline$j=1:$ Machining & 47 & 64 & 64 & 67 & 0.25 \\
$j=2$ : Electroless Plating & 33 & 33 & 33 & 37 & 0.49 \\
$j=3$ : Electroplating & 45 & 50 & 35 & 50 & 0.23 \\
$j=4:$ Etch & 43 & 60 & 47 & 49 & 0.08 \\
$j=5$ : Automated Assembly & 41 & 58 & 100 & 55 & 0.17 \\
$j=6$ : Manual Assembly & 8 & 15 & 60 & 14 & 1.01 \\
$j=7:$ Test and Tune & 180 & 330 & 330 & 237 & 0.13 \\
\hline
\end{tabular}

Table 3: Desired Product Throughput

\begin{tabular}{||l|c|c|c||}
\hline Product $i$ & 1 & 2 & 3 \\
\hline Throughput $T_{i}$ (parts/hour) & 2.5 & 2.5 & 0.625 \\
Batch size $B_{i}$ (parts/batch) & 5 & 10 & 10 \\
Release rate $x_{i}$ (batches/hour) & 0.5 & 0.25 & 0.0625 \\
\hline
\end{tabular}

workstation has a screen print machine, a pick-and-place machine, and a reflow oven. The material handling between these machines is automated. The manual assembly workstation has two employees who can attach other component types. The facility has four technicians who test and tune microwave modules. All resources are perfectly reliable $\left(A_{j}=1\right)$.

\subsection{Capacity Analysis}

The queuing network model presented above yields the average resource utilization at each station. Table 4 displays these results. Since all $u_{j}<1$, all of the stations have sufficient capacity to process the new product.

Table 4: Resource Utilization

\begin{tabular}{||l|c|c||}
\hline Station & $j$ & Util. $u_{j}$ \\
\hline Machining & 1 & 0.90 \\
Electroless Plating & 2 & 0.50 \\
Electroplating & 3 & 0.68 \\
Etch & 4 & 0.66 \\
Auto. Assembly & 5 & 0.74 \\
Manual Assembly & 6 & 0.09 \\
Test and Tune & 7 & 0.80 \\
\hline
\end{tabular}


Table 5: Throughput Time Estimates: Queuing Network Model

\begin{tabular}{||l|c|c|c|c||}
\hline Station & $j$ & $\begin{array}{c}\text { Throughput Time } \\
\text { (mins) } T T_{j}^{*}\end{array}$ & $\begin{array}{c}\text { Multiple } \\
M_{j}\end{array}$ & $\begin{array}{c}\text { Sensitivity } \\
S_{3 j}\end{array}$ \\
\hline Machining & 1 & 438 & 6.58 & 6.33 \\
Electroless Plating & 2 & 53 & 1.43 & 1.24 \\
Electroplating & 3 & 85 & 1.68 & 1.41 \\
Etch & 4 & 69 & 1.41 & 1.09 \\
Auto. Assembly & 5 & 85 & 1.56 & 1.30 \\
Manual Assembly & 6 & 14 & 1.01 & 0.78 \\
Test and Tune & 7 & 268 & 1.13 & 0.87 \\
\hline Total & & 1012 & & \\
\hline
\end{tabular}

\subsection{Estimating the Throughput Time}

The queuing network model estimates the throughput time at each station and for the new product. Table 5 summarizes queuing network model estimates of the average throughput time at each workstation. The total is 1012 minutes, or 16.9 hours. This table also shows the throughput time multiple and the sensitivity for the new product. Note that the machining and testing stations have the largest throughput times. The machining station has the largest throughput time multiple, and sensitivity.

\subsection{Redesign Suggestions}

Based on these results the product development team might investigate the machining and testing operations. The utilization, throughput times, and throughput time multiples are all large. The team might consider redesigning the product to reduce the machining requirements by reducing the number of holes and pockets. Substitute components may not need these features. In addition, the team might consider redesigning the product to make testing and tuning simpler. Other options include purchasing tools and equipment that will simplify testing and tuning, and retraining a manual assembly person to perform testing (since the manual assembly area is not busy).

For comparison, the product development team can view a baseline scenario by setting the desired throughput of Product 3 to zero. Table 6 shows the average throughput time at each station before the facility manufactures Product 3 and after the facility adds Product 3 . As may be seen, the machining operation has the largest change throughput time, and a dominant portion of the total throughput time increase occurs at that station. The product development team can, in addition, determine the effect of adding a second CNC machine tool. Table 6 shows the average throughput time at each station in that scenario also. The average throughput time at machining decreases greatly, while the average throughput times 
Table 6: Throughput Time Comparison

\begin{tabular}{||l|c|c|c||}
\hline \multirow{2}{*}{ Station } & \multicolumn{3}{|c||}{ Average Throughput Time (mins) } \\
\cline { 2 - 4 } & $\begin{array}{c}\text { Two } \\
\text { Products }\end{array}$ & $\begin{array}{c}\text { Three } \\
\text { Products }\end{array}$ & $\begin{array}{c}\text { Two } \\
\text { Tools }\end{array}$ \\
\hline Machining & 253 & 438 & 77 \\
Electroless Plating & 52 & 53 & 61 \\
Electroplating & 84 & 85 & 104 \\
Etch & 68 & 69 & 78 \\
Automated Assembly & 66 & 85 & 93 \\
Manual Assembly & 10 & 14 & 14 \\
Test and Tune & 246 & 268 & 272 \\
\hline Total & 779 & 1012 & 699 \\
\hline
\end{tabular}

at some other stations increase slightly due to increased variability.

\section{Summary and Conclusions}

This paper presented a specific approach that determines how manufacturing a new product design affects the performance of the manufacturing system. Design for production (DFP) includes design guidelines, capacity analysis, and estimating throughput times. Performing these tasks, like other DFM techniques, early in the product development process can reduce product development time.

Previous researchers have developed various DFP methods for different problem settings. This paper discussed the relevant literature and classifies these methods. The paper presented a DFP approach that incorporates both capacity analysis and throughput time analysis, and the approach provides feedback on mitigating throughput time problems. The approach, unlike previous DFP approaches, uses a queuing network model to estimate the throughput time of a new product and the congestion that the new product introduces at each workstation. This paper focused on products that follow a simple routing and are produced in one facility. An example illustrated the DFP approach.

Future work needs to specify models for complex assemblies and for settings where the manufacturing system of interest includes multiple manufacturing facilities. These settings will become more important as products are designed for supply chains and virtual enterprises.

The DFX methodology [16] uses information about the performance of a product design during downstream processes to improve the product design. Information from a number of such processes as manufacturing and assembly is used for the purpose. The models and methods presented in this paper can be added to this information to help a designer make tradeoffs between different designs (or redesign suggestions) and select the one that optimizes require- 
ments of performance, manufacturing cost, and time along with other life-cycle requirements. In addition, the approach could be applied to integrate decision support for manufacturing system design when a new facility will be constructed to make the new product.

\section{References}

[1] Bakerjian, R., editor, Design for Manufacturability, Tool and Manufacturing Engineers Handbook, Volume 6, Society of Manufacturing Engineers, 1992.

[2] Bermon, S., G. Feigin, and S. Hood, "Capacity analysis of complex manufacturing facilities," Proceedings of the 34th Conference on Decision and Control, pages 1935-1940, New Orleans, Louisiana, December, 1995.

[3] Bolz, Roger W. Production Processes: Their Influence on Design. The Penton Publishing Company, Cleveland, 1949.

[4] Boothroyd, G., P. Dewhurst, and W. Knight, Product Design for Manufacture and Assembly, Marcel Dekker, New York, 1994.

[5] Bralla, J.G., Ed. Handbook of Product Design for Manufacturing. McGraw-Hill Book Company, New York, 1986.

[6] Buzacott, J.A., and J.G. Shanthikumar, Stochastic Models of Manufacturing Systems, Prentice-Hall, Englewood Cliffs, New Jersey, 1993.

[7] Candadai, A., J.W. Herrmann, I. Minis, "A group technology-based variant approach for agile manufacturing," in Concurrent Product and Process Engineering, Proceedings of the International Mechanical Engineering Congress and Exposition, San Francisco, California, November 12-17, 1995.

[8] Candadai, A., J.W. Herrmann, and I. Minis, "Applications of Group Technology in Distributed Manufacturing," Journal of Intelligent Manufacturing, Volume 7, pages 271291, 1996.

[9] Connors, Daniel P., Gerald E. Feigin, and David D. Yao, "A queuing network model for semiconductor manufacturing," IEEE Transactions on Semiconductor Manufacturing, Volume 9, Number 3, pages 412-427, 1996.

[10] Elhafsi, Mohsen, and Erik Rolland, "Negotiating price and delivery date in a stochastic manufacturing environment," IIE Transactions, Volume 31, pages 255-270, 1999. 
[11] Govil, Manish Kumar, "Integrating Product Design and Production: Designing for Time-to-Market," Ph.D. dissertation, Department of Mechanical Engineering, University of Maryland, College Park, 1999.

[12] Gupta, S.K., and D. S. Nau. "A systematic approach for analyzing the manufacturability of machined parts." Computer Aided Design, 27(5), pages 323-342, 1995.

[13] Gupta, S.K., D. S. Nau, W. C. Regli, and G. Zhang. "A methodology for systematic generation and evaluation of alternative operation plans." in Jami Shah, Martti Mantyla, and Dana Nau, editors, Advances in Feature Based Manufacturing, pages 161-184. Elsevier/North Holland, 1994.

[14] Hayes, C.C., S. Desa, and P. K. Wright. "Using process planning knowledge to make design suggestions concurrently." In N. H. Chao and S. C. Y. Lu, editors, Concurrent Product and Process Design, ASME Winter Annual Meeting, pages 87-92. ASME, 1989.

[15] Hayes, C.C., and H. C. Sun. "Plan-based generation of design suggestions." In R. Gadh, editor, Concurrent Product Design, ASME Winter Annual Meeting, pages 59-69, Design Engineering Division, ASME, New York, 1994.

[16] Herrmann, Jeffrey W., and Mandar Chincholkar, "Models for estimating manufacturing cycle time during product design," in Proceedings of the International Conference on Flexible Automation and Intelligent Manufacturing, College Park, Maryland, June 26$28,2000$.

[17] Herrmann, J.W., G. Lam, and I. Minis, "Manufacturability analysis using high-level process planning," in Proceedings of the 1996 ASME Design for Manufacturing Conference, University of California, Irvine, August 18-22, 1996.

[18] Hopp, Wallace J., and Mark L. Spearman, Factory Physics, Irwin/McGraw-Hill, Boston, 1996.

[19] Hsu, Wynne, C. S. George Lee, and S. F. Su. "Feedback approach to design for assembly by evaluation of assembly plan." Computer Aided Design, 25(7):395-410, July 1993.

[20] Ishii, Kosuke. "Modeling of concurrent engineering design." In Andrew Kusiak, editor, Concurrent Engineering: Automation, Tools and Techniques, pages 19-39. John Wiley \& Sons, Inc., 1993.

[21] Jakiela, M., and P. Papalambros. "Design and implementation of a prototype intelligent CAD system." ASME Journal of Mechanisms, Transmission, and Automation in Design, 111(2), June 1989. 
[22] Kalpakjian, S., Manufacturing Processes for Engineering Materials, Addison Wesley, Reading, Massachusetts, 1984.

[23] Koo, P.-H., C.L. Moodie, and J.J. Talavage, "A spreadsheet model approach for integrating static capacity planning and stochastic queuing models," International Journal of Production Research, Volume 33, Number 5, pages 1369-1385, 1995.

[24] Kusiak, Andrew, and Weihua He, "Design of components for schedulability," European Journal of Operational Research, Volume 76, pages 49-59, 1994.

[25] Law, Averill M., and W. David Kelton, Simulation Modeling and Analysis, 2nd edition, McGraw-Hill, New York, 1991.

[26] Lee, Hau L., Corey Billington, and Brent Carter, "Hewlett-Packard gains control of inventory and service through design for localization," Interfaces, Volume 23, Number 4, pages 1-11, 1993.

[27] Meyer, J., M. Ball, J. Baras, A. Chowdhury, E. Lin, D. Nau, R. Rajamani and V. Trichur, "Process Planning in Microwave Module Production," in 1998 Artificial Intelligence and Manufacturing: State of the Art and State of Practice, September, 1998.

[28] Minis, I., J.W. Herrmann, G. Lam, and E. Lin, "A generative approach for concurrent manufacturability evaluation and subcontractor selection," in Journal of Manufacturing Systems, Volume 18, Number 6, pages 383-395, 1999.

[29] Nielsen, Niels Peter Heeser, and Jan Holmstrom, "Design for speed: a supply chain perspective on design for manufacturability," Computer Integrated Manufacturing Systems, Volume 8, Number 3, pages 223-228, 1995.

[30] G. Pahl and W. Beitz. Engineering Design. Design Council, London, 1984.

[31] Papadopoulos, H.T., C. Heavey, and J. Browne, Queuing Theory in Manufacturing Systems Analysis and Design, Chapman and Hall, London, 1993.

[32] Rosen, David W., John R. Dixon, Corrado Poli, and Xin Dong. "Features and algorithms for tooling cost evaluation in injection molding and die casting." In Proceedings of the ASME International Computers in Engineering Conference, pages 1-8. ASME, 1992.

[33] Seepersad, C.C., G.Hernandez and J.K.Allen, "A quantitative approach to determining product platform extent," paper DETC2000/DAC-14288 in CD-ROM Proceedings of DETC 2000, 2000 ASME Design Engineering Technical Conference, pages 1-10, Baltimore, September 10-13, 2000. 
[34] Schilling, Melissa A., and Charles W.L. Hill, "Managing the new product development process: strategic imperatives," IEEE Engineering Management Review, pages 55-68, Winter, 1998.

[35] Singh, Nanua, Systems Approach to Computer-Integrated Design and Manufacturing, John Wiley and Sons, New York, 1996.

[36] Soundar, P., and Han P. Bao, "Concurrent design of products for manufacturing system performance," Proceedings of the IEEE 1994 International Engineering Management Conference, pages 233-240, Dayton, Ohio, October 17-19, 1994.

[37] Suri, Rajan, "Lead time reduction through rapid modeling," Manufacturing Systems, pages 66-68, July, 1989.

[38] Taylor, D.G., English, J.R., and Graves, R.J., "Designing new products: Compatibility with existing product facilities and anticipated product mix," Integrated Manufacturing Systems, Volume 5, Number 4/5, pages 13-21, 1994.

[39] H. E. Trucks. Designing for Economic Production. Society of Manufacturing Engineers, 1987.

[40] Veeramani, Dharmaraj, and Pawan Joshi, "Methodologies for rapid and effective response to requests for quotation," IIE Transactions, Volume 29, pages 825-838, 1997.

[41] Veeramani, Dharmaraj, and Tushar Mehendale, "Online design and price quotations for complex product assemblies: the case of overhead cranes," 1999 ASME Design for Manufacturing Conference, Las Vegas, Nevada, September 12-15, 1999.

[42] Vollmann, Thomas E., William L. Berry, and D. Clay Whybark, Manufacturing Planning and Control Systems, 4th edition, Irwin/McGraw-Hill, New York, 1997. 


\section{Author's Biographies}

Jeffrey W. Herrmann is an associate professor in the Department of Mechanical Engineering and the Institute for Systems Research at the University of Maryland. He is the director of the Computer Integrated Manufacturing Laboratory. He earned his B.S. in applied mathematics from Georgia Institute of Technology. As a National Science Foundation Graduate Research Fellow from 1990 to 1993, he received his Ph.D. in industrial and systems engineering from the University of Florida. His publications cover topics in process planning, production scheduling, manufacturability evaluation, and manufacturing facility design. His current research interests include the design and control of manufacturing systems and the integration of product design and manufacturing system design.

Mandar M. Chincholkar is a doctoral candidate in the Computer Integrated Manufacturing Laboratory at the University of Maryland. He graduated with a master's degree in mechanical engineering (design engineering) from the Indian Institute of Technology, Bombay. His research interests include computer aided design and manufacturing, integrated product and manufacturing systems design and geometric modeling. 